\title{
Türkiye'de Kazak Kültür ve Tarihi Hakkındaki Çalışmalara Bir Bakış
}

\author{
A Review of Studies About Kazakh Culture and History in \\ Turkey
}

\section{Cafer GÜLER*}

$\ddot{O} z$

Türkiye'de Türkiyat araşttrmaları Cumhuriyet döneminde hiz ve yoğunluk kazanmıştır. Türkiyat araştırmalarının önemli bir kolunu ise Türkiye dışındaki Türk topluluklarının tarih ve kültürü oluşturmuştur. Osmanlı'dan Cumhuriyet'e geçişte varlğ̆ın sürdüren Türk Ocağı ve yayın organı Türk Yurdu 1924'te Darülfünun'a bağlı Türkiyat Enstitüsü ve yayın organı olan Türkiyat Mecmuası'nda Türk dünyası tarihi ve kültürü hakktndaki çalışmalara rastllyoruz. 1930'lu yıllardan itibaren çıkmaya başlayan ve 1939-1945 arası yoğunluk kazanan Türkçü dergilerde yine aynı şekilde konumuzla ilgili yazıları görmek mümkündür. Akademik planda ise 1936'da öğretime başlayan D.T.C.F.nin Türk Dili ve Edebiyatı bölümünde Abdülkadir İnan, Saadet Çağatay Kazakça'yı da içine alan Türk lehçelerini okutmuşlardır ve bu konuda yayın yapmışlardır. 1961 ile 1991 arası dönemde özellikle Türk Kültürü̈nü Araştırma Enstitüsü ve Türk Dünyası Araştırmaları Vakfi Dış Türkler çerçevesinde Kazak tarihi ve kültürü hakkında önemli çalışmalara imza atmışlardl. Sovyetler Birliği'nin dağılmasıyla birlikte Türkiye'de diğer Türk devlet ve topluluklarının yanı sıra Kazak tarihi ve kültürü hakkinda gerek resmi kurum ve kuruluşlar, gerekse özel vakiflar ve enstitüler ile yayınevleri telif ve çeviri yoluyla çok yoğun bir yayın patlaması gerçekleştirmişlerdir. Bu dönemde genel nitelikte Türk bilim adamları tarafindan Kazak tarihi ve kültürüne ait eserler verilmiştir. Cumhuriyet döneminde 80 yll aş̧kn telif ve çeviri yoluyla Kazak tarihi ve kültürü hakkında önemli bir bilgi birikimine ulaşılmıştır. Türk araştırmacıların daha ayrintılı monografileri kaleme almalarında bir engel gözükmemektedir.

* Dr. A.̈̈. Dil ve Tarih-Coğrafya Fakültesi Tarih Bölümü Türkiye Cumhuriyeti Tarihi Anabilim Dall. 
Anahtar kelimeler: Türkiye'de Türkoloji, Kazaklar, Kazakistan

\begin{abstract}
Turkological researches gained speed and intensity in the period of Republic. A significant branch of Tturkology studies was in the field of history and culture of Turkic groups outside of Turkey. Continued presence of Türk Ocağı and its press organ Türk Yurdu during transition from Otoman Empire to Republic and in Turkology Institute and its press organTürkiyat Mecmuast we can see studies about Turkish world history and culture. Also we can see articles on this topic in Turkist magazines which started to publish from 1930s and gained intensity during 19391945. In academic field, A. Inan and Saadet Çağatay gave lessons and published books on Turkic dialects including Kazakh in Ankara University Faculty of Language, Geography and History which opened in 1936. In the period between 1961 and 1991, the Institute for Research of Turkic Culture and Foundation for Research on Turkic World conducted important researches about Foreign Turks within the framework of history and culture of Kazakhs. After the collapse of Soviet Union there was huge intensification on studies about history and culture of other Turkic nations including Kazakhs by means of official organs and ministries, assosiations, foundations and press houses. During this period, there were studies of general nature conducted by Turkish scientists related to history and culture of Kazakhs. Over 80 years in the period of the Republic there has been a significant accumulation about history and culture of Kazakhs by copyright and translation works. There seems no obstacle to make more detailed, deeper studies and monographs about Kazakh history and culture
\end{abstract}

Keywords: Turkology in Turkey, Kazakhs, Kazakhstan.

\title{
Giriş
}

Bu makalenin amac1, Türkiye'de 1923'ten 2007'ye kadar geçen sürede Kazakistan tarihi ve kültürü hakkında çıkmış olan telif veya çeviri yayınlara ilişkin bazı gözlem ve değerlendirmelerde bulunmaktır.

Bununla birlikte bu çalışmanın konuyla ilgili eksiksiz bibliyografya vermek gibi bir amacı bulunmamaktadır'. Yapılmak istenen, Türkiye'de Türk Dünyası araştırmalarının bir parçası olarak Kazakistan'la ilgili yayınların belli başlılarına işaret ederek bazı sonuçlara varmaktır. Örneğin Kazakistan'la ilgili yayınların hangi yıllarda dönemlerde yoğunlaştı̆̆ 1 , hangi kurum dernek veya vakıfların bu yayınlara önayak olduğu, hangi kişi ve grupların bu yayınlarda sivrildiğini ortaya çıkarmak gibi.

\footnotetext{
${ }^{1}$ Bu konu ile ilgili, sayı olarak hayli fazla olan makaleleri, bir başka makale şeklinde işlemeyi düşünmekteyiz. Bu çalışmada bazı makalelere işaret etmekle yetindik.
} 
Bundan dolayı, bu makale Türkiye'de Türk dünyası araştırmalarının gelişimi gibi kapsamlı bir monografinin konusu olabilecek bir çalışmaya Kazakistan araştırmaları örneği ile bir katkı yapmak amacını gütmektedir.

\section{Bölüm: 1924-1938}

Türkiye Cumhuriyeti'nin kuruluşundan Atatürk'ün ölümüne değin uzanan yılları, genç Cumhuriyet'in milli devlet olarak kurulup geliştiği dönem olarak tanımlamak yanlış olmaz. Bu dönemde Atatürk'ün tarihe duyduğu ilginin temelinde milli devletin kültürel altyapısını güçlendirmek vardır. Daha 1924'te o zamanki adıyla Darülfünun olan İstanbul Üniversitesine bağlı Türkiyat Enstitüsü 1924 'te bakanlar kurulu kararı ile kurulacaktır $^{2}$. Bu Enstitü'nün müdürlüğüne Fuat Köprülü ${ }^{3}$ getirilecek, Türkiyat Mecmuası yayımlanacaktır. Enstitü 1926'da ünlü Rus Türkolog Barthold'u davet eder ve Barthold konferanslar verir. Bu konferanslar Orta Asya Türk Tarihi Hakkında Dersler adıyla basılır. (Barthold 1927). Bu derslerde içinde Kazakistan coğrafyasının da bulunduğu bölgelerin eski zamanlardan yeni zamanlara kadar siyasi, sosyo-ekonomik ve kültürel hayatı anlat1lir.

Türkiye'de Türkçülük akımının öncülerinden biri olan Yusuf Akçura 'nın Türk Ocakları ${ }^{5}$ yayınlarından çıkan Türk Yılı başlıklı derlemesi hayli hacimli olan derleme, hem geçmişi hem de 1928'deki Türk dünyasının durumunu tespit eden ilk geniş kapsamlı almanak olma özelliğini taşımaktadır. (Akçura: 1928)

Dönemin ilk yarısında dikkat çeken gelişmelerden birisi Zeki Velidi $\operatorname{Togan}^{6}$ ve Abdülkadir İnan ${ }^{7}$ in Türkiye'ye gelmeleridir. Abdülkadir İnan Türkiyat Enstitüsü'nde, Togan Tarih bölümünde görev alırlar.

1930'lu yıllarda Türk dünyası ile ilgili yazıların yer aldığı popüler nitelikte dergiler çıkmaya başlıyor. Bu dergiler Türk kamuoyunun Türkiye dışındaki Türk topluluklarına yönelik ilgisini canlı tutmak bakımından yararlı olmuşlardır. Türkiyat Enstitüsü’nde bir süre F. Köprülü’nün

2 Türkiyat Enstitüsü hakkında, bu enstitünün çıkardığı tanıtım broşürü için bkz. (İstanbul Darülfünunu Türkiyat Enstitüsü: 1931. Ayrıca (İlgürel, 1975).

${ }^{3}$ Fuat Köprülü 1918 yılında Hoca Ahmet Yesevi ve onun tasavvuf tarihindeki yerini ayrıntılı olarak incelediği Türk Edebiyatında İlk Mutasavviflar kitabını yayınlayarak haklı bir üne kavuşur. Türk Edebiyatı Tarihi, Türk Tarihi ve halkbilimi konularına ait değerli eserleri bulunan Fuat Köprülü hakkında bkz. (Bilgiç,Eren ve Turan, 1953).

${ }^{4}$ Yusuf Akçura hakkında yarıntılı bilgi için bkz. (Georgeon, 1986).

${ }^{5}$ Türk Ocakları hakkında bkz. (Sarınay, 2004).

${ }^{6}$ Zeki Velidi Togan hakkında yarıntılı bilgi için bkz. (60. Doğum Yılı Münasabetiyle Zeki Velidi Togan'a Armağan, 1950); (Baykara, 1986).

${ }^{7}$ (Çoker, 1983: 667-684); (İnan, 1968). 
asistanlığını yapan Hüseyin Nihal Atsız $^{8}$ 1931-32'de Atsız Mecmua'y1, 1934'te Orhun adlı dergileri çıkarır'.

$\mathrm{Bu}$ dönemde Türk dünyası ile ilgili genel nitelikli iki çalışma yapılmıştır. Birincisi Hüseyin Namık Orkun'un Türk Dünyası (Orkun, 1932), diğeri ise A. Yaylagil ve Münir Haymana'nın Halihazırda Türk Topluluklar ve Pan Türklüge Dair, (Yaylagil-Haymana: 1937) adlı eserdir. Bu çalışmada Türkistan coğrafyası içinde Kazaklardan bahsedilir.

Akademik alanda Kazak tarihi, Kazakça ve Kazak kültürü,1936 yılında öğretime başlayan D.T.C.F.'de okutulmaya başlanacaktır. Atatürk'ün isteği ile Türk Dili ve Edebiyatı bölümünde görev alan Abdulkadir İnan, içinde Kazakça'nın da bulunduğu Türk Lehçelerini okutmuştur. Ayrıca İnan, dergilerde Kazak tarihi ve kültürü hakkında çeşitli yayınlar yapacaktır.

\section{Bölüm: 1938-1945}

$\mathrm{Bu}$ dönem süre olarak kısa olmasına rağmen, Kazakların ve Kazakların bulunduğu Türkistan coğrafyası ile kamuoyunun yakından ilgilenilmesi açısından popüler nitelikte dergiciliğin patlama yaptığı bir dönem olarak önemlidir.

Bütün bu dergilerde ${ }^{10}$ Kazaklar ve Kazakistan topraklarının da bulunduğu Türkistan coğrafyası ve topluluklardan bahsedilmiştir. $\mathrm{Bu}$ dergiler Reha Oğuz Türkkan Ergenekon (1938-1939) Bozkurt (1938-1942), Gökbörü (1942-1943). Dr. Riza Nur'un Tanrıdăg (1942), Ahmet Caferoğlu'nun Türk Amacı (1942-1943). Nihal Atsız'in Orhun (1943-1944), Orhan Seyfi Orhon-Yusuf Ziya Ortaç'ın Çınaraltı (1941-1944) dergileri çıkmıştır.

Akademik dünyada ise Almanya'dan Türkiye'ye dönen ve İ.Ü. Edebiyat Fakültesi'nde Tarih Bölümü'nde yeniden görev alan Zeki Velidi Togan bu dönemde konumuzla ilgili iki eser vermiştir. Birincisi Kazak coğrafyasını da içine alan Türkistan'ın tarihi hakkındaki önemli eseri olan Bugünkü Türkili -Türkistan- ve Yakın Tarihi (Togan: 1942) ve Sovyet döneminde Türkistan'1 anlatan 1929-1940 Seneleri Arasinda Türkistan Vaziyeti adlı eseridir. (Togan: 1940). Ankara'da ise D.T.C.F. Türk Dili ve Edebiyatı bölümünde Abdülkadir İnan Kazakça'nın da olduğu Türk lehçelerini oluşturmaya devam etmiştir. Diğer yandan D.T.C.F Macar Dili

\footnotetext{
${ }^{8}$ Hüseyin Nihal Atsız hakkında bkz. (Atsız Armağanı, 1976)

9 Atsız'ın bu dönemde çıkardığı dergiler için bkz. (Darendelioğlu, 1968: 74-75); (Landau, 1999: 129-130).

${ }^{10}$ Bu yıllarda çıkan Türkçü dergiler için bkz. (Darendelioğlu, 1968: 202-208); (Landau, 1999: 130-142).
} 
Kürsüsü'nde ders veren Laszlo Rasonyi'nin Dünya Tarihinde Türklük, (Rasonyi 1942) başlıklı genel nitelikli bir eseri basılmıştır.

$\mathrm{Bu}$ y1llarda Kazaklardan da bahseden genel nitelikli çalışma Hüseyin Namık Orkun'a aittir: Yeryüzünde Türkler (Orkun: 1944). Ayrıca bahsedilmesi gereken kitap ise Abdullah Recep Baysun'nun Türkistan Milli Hareketleri (Baysun: 1943) adlı çalışmasıdır. Burada genel nitelikli olmakla birlikte Kazak toplumundan bahis var.

\section{Bölüm: 1945-1961}

Bu dönemde de 1928-1945 arası dönemde olduğu gibi Türkçü dergiler çıkarılmasına devam edilir. Bu dergilerde Kazaklar ve Kazak coğrafyasının da bulunduğu Sovyet egemenliği altındaki bölge ve halkları hakkında yazılar vardır.Bu dergilerin belli başlıları şunlardır: Türkeli, Kür Şad, Bozkurt, Tanrıdăg, Türk Dünyası Bölünmez Bütün, Özleyiş, Toprak, Altınışık, Çınaraltı, Orkun ${ }^{11}$.

Akademik planda D.T.C.F.de Türk Dili ve Edebiyatı Bölümünde Abdülkadir İnan'dan sonra Saadet Çağatay ${ }^{12}$ Türk Lehçeleri dersini okutmaya başlayacaktır. Aynı zamanda S. Çağatay, okuttuğu bu ders için kitaplar da hazırlayacaktır. Örneğin, Türk Lehçeleri Örnekleri VIII. Yüzyıldan XVIII. Yüzyıla Kadar Yazı Dili Örnekleri (Çağatay: 1950). Ayrıca Kazakistan coğrafyası ile de ilgili bilgiler veren Macar bilim adamı Lajos Ligeti'nin Bilinmeyen $\dot{I}_{c ̧}$ Asya adlı eseri çevrilerek D.T.C.F yayını olarak basılmıştır. (Ligeti, 1946)

İ.Ü. Edebiyat Fakültesi Tarih Bölümü'nde ders vermeye devam eden Zeki Velidi Togan'ın Umumi Türk Tarihine Giriş (Togan, 1946) önemli bir genel nitelikli Türk Tarihi çalışmasıdır. Aynı fakülteden Türk Dili ve Edebiyatı Bölümü'nde görev yapan Reşit Rahmeti Arat'ın İslam Ansiklopedisi'nde yazmış olduğu Kazakistan maddesi de Türkçe'de konu ile ilgili derli toplu bir çalışmadır. (Arat,: 1955)

Diğer yandan bu yıllarda hem Kazak Türkü'nün bağımsızlık önderlerinden Mustafa Çokay hem de genel planda Türkistan bağımsızlık hareketleri hakkında eserler verilmiştir: Türkistan Milli Hareketi ve Mustafa Çokay (Oktay 1950). Yine A. Oktay'ın Türkistan'a dair bazı cereyanlar hakkında görüşlerimiz (Oktay: 1952) Y.T.nin Türkistan'da Türkçülük ve Halkçılık (Ed. A. Oktay, 1951-54) başlıklı 2 ciltlik eser de vurgulanması gereken çalışmalardandır.

\footnotetext{
${ }^{11}$ Bu yıllarda çıkan Türkçü dergiler için bkz. (Darendelioğlu, 1968: 208-212); (Landau, 1999: 185-189).

${ }^{12}$ Saadet Çağatay hakkında bkz. (Özdemir ve Şenol, 2006: 103-152).
} 


\section{Bölüm: 1961-1991}

Bu 30 yıllık dönemi 1961de başlatmamızın nedeni Türk dünyasıyla geniş ve yoğun bir şekilde ilgilenmeyi amaçlayan Türk Kültürünü Araştırma Enstitüsünün kuruluş yılının olmasıdır. Enstitü İstanbul ve Ankara üniversitelerine mensup bir grup bilim adamı tarafindan kurulur. Enstitü aylık Türk Kültürü adlıyla yayın organı çıkaracaktı1 ${ }^{13}$.

Enstitünün en önemli çalışmalarından birisi 1976da oldukça hacimli Türk Dünyası El Kitabı'nı yayınlatmış olmasıdır. Türk dünyası coğrafyası tarihi, kültürü hakkında derli toplu ilk Türkçe kitaptır (TKAE 1976). Bu çalışmada Kazak dili edebiyatı ve tarihi, coğrafyasından da bahisler vardır. Enstitünün yukarıda bahsettiğimiz Türk Kültürü adlı aylık dergide Kazak tarihi ve kültüründen bahis vardır. Örneğin Ahmet Caferoğlu'nun Kazak Türkleri hakkında makalesi (Caferoğlu: 1965), Hasan Oraltay'ın “Kazak Türklerinin Çadırları" (Oraltay: 1978).

İkinci kurum Türk Dünyası Araştırmaları Vakfıdır ${ }^{14}$. Bu vakıf, 1980'de İstanbul Üniversitesi İktisat Fakültesi'nde Prof. Dr. Turan Yazgan'ın öncülüğünde kurulmuştur. İki önemli dergi çıkarmıştır. Türk Dünyası Araştırmaları Dergisi ve Türk Dünyası Tarihi Dergisi Vakfın konumuzla ilgili önemli bir yayını Hasan Oraltay'ın Kazak Türkçesi Sözlüğ̈̈'dür (Oraltay: 1984).

Türkiye dışındaki Türk topluluklarıyla ilgili yayın yapan ve Türk kamuoyunu bilgilendiren popüler nitelikteki dergi yayıncılığı bu dönemde de devam etmiştir ${ }^{15}$. Bu dergileri şöyle sıralayabiliriz: Türk Birliği (1966-1971), Ötüken (1964-1975), Adsız (1972'den itibaren), Türk'e Çağrl (1979'dan itibaren), Turan (1976'dan itibaren), Hür Türkistan Iç̧in İstiklalci Gazete (1975-1976), Dilde Fikirde İşte Birlik (1977'den itibaren), Töre (1971'den itibaren)

Akademik dünyada ise Ankara Üniversitesi D.T.C.F.de Türk Dili ve Edebiyatı bölümünde Saadet Çağatay- 1950de yayınladığı Türk Lehçeleri dersini vermeye devam etmiştir. Çağatay, ayrıca okuttuğu bu dersle ilgili kitaplar da çıkarmıştır: Türk Lehçeleri Örnekleri (Çağatay: 1972) Türk Lehçeleri Üzerine Denemeler (Çağatay: 1978) S.Çağatay ayrıca 1961de D.T.C.F. yayını olarak Kazakça Metinler'i yayınlamışır. (Çağatay: 1961). Hacettepe Üniversitesi'nden Ahmet Bican Ercilasun'un Bugünkü Türk Alfabeleri (Ercilasun: 1977) Kültür Bakanlığı tarafından yayınlanmıştır.

\footnotetext{
${ }^{13}$ Enstitü hakkında bkz. (Landau, 1999: 234-236)

${ }^{14}$ Vakıf hakkında bkz. . http://www.turan.org.tr

${ }^{15} \mathrm{Bu}$ yıllarda çıkan popüler Türkçü dergiler için bkz. (Darendelioğlu, 1968: 374); (Landau, 1999: 236-243).
} 
Marmara Üniversitesi'nde Türkiyat Araştırmaları Merkezi 1985'te kurulur. Merkezin 1987 'de önemli bir yayın faaliyeti Dünyada Türklük Araştırmaları ve Türkiye başlıklı çalışma.

İstanbul Üniversitesi'nde, Zeki Velidi Togan'ın Hatıralar (Togan: 1969) ve yayınlanan diğer eseri Türklü̆̆̈̈n Mukadderatı Üzerine (Togan: 1970). Kazakları da ilgilendiren Türkistan'ın Sovyet egemenliğine girmesi hakkında önemli çalışmalardır. İ.Ü. Edebiyat Fakültesi Tarih bölümünden Mehmet Saray ve Coğrafya bölümünden Yusuf Dönmez'in araştırmaları öne çıkıyor. M. Saray'ın iki monografisi önemli. Bunlar Rusya 'nın Türk İlerinde Yayılması (Saray: 1975) ve Rus işgali döneminde Osmanlı Devleti ile Türkistan Hanlıklarl Arasındaki Siyasi Münasebetler (1775-1875).(Saray: 1984).Saray'ın ayrıca İslam Ansiklopedisi'nde cilt 12/2 Dış Türkler maddesi de önemlidir. Yusuf Dönmez'in şu monografisi önemlidir: Türk Dünyasının Beşeri ve İktisadi Coğrafyası, (Dönmez: 1987).

Marmara Üniversitesi öğretim üyelerinden Nadir Devlet'in şu eseri de vurgulanmalıdır: Rusya Türklerinin Milli Mücadele Tarihi (1905-1917). (Devlet, 1985). Bu çalışmada Kazakların da mücadelesinden bahisler vardır. Yine aynı yazarın genel nitelikli şu eseri de önemlidir: Çağdaş Türk Dünyas1, (Devlet, 1989).

$\mathrm{Bu}$ dönemde yukarıda bahsedilen kurumlar ve üniversiteler dışında konumuzla ilgili önemli çalışmaları olan kişiler arasında Hasan Oraltay ${ }^{16}$ ismi ön plana çıkıyor. Hasan Oraltay'ın Kazak Türkçesi sözlüğünden yukarıda bahsetmiştik. Oraltay'ın diğer eserleri şunlardır: Kazak Türkleri Hürriyet Ŭgrunda Doğu Türkistan, (Oraltay 1961); Alaş Türkistan Türklerinin Milli İstiklal Parolası, (Oraltay: 1973).

Bu dönemin önemli bir eseri de Muhabay Engin'in editörlüğünü yaptığ 1 Kazak ve Tatar Türkleri'dir. (Ed.Engin, 1976). Sovyet egemenliği altındaki Türk dünyası'na ilişkin Baymirza Hayit'in hacimli bir çalışması olan Türkistan Rusya ile Çin Arasında önemli bir çalışmadır (Hayit1975). Hayit'in bir başka çalışması Türkistan'da Öldürülen Türk Şairleri'dir. (Hayit: 1971)

$\mathrm{Bu}$ dönemin sonlarına doğru Kazakistan'da 1986 aralık ayında çıkan olaylar Türkiye'de de yankı bulmuş, konu hakkında kitap ve makaleler çıkmıştır. Örneğin daha önceki bölümlerde bahsettiğimiz Türk Ocağı'nın çıkarmakta olduğu Türk Yurdu dergisinde 1986 Aralık ayı olaylarına ait makaleler çıkmıştır. Örneğin Mahmut Alanbek "Kazakistan'da İsyan"

\footnotetext{
${ }^{16}$ Hasan Oraltay Doğu Türkistan'daki Kazak Türklerinden olup 1950’lerde Türkiye’ye göç eden bir aileye mensuptur. Kazak tarihi, dili, kültürü hakkında hayli eser vermiştir. Oraltay ve ailesi hakkında bkz. http://www.alibeghakim.com
} 
(Alanbek, 1987) ve Suat Temiz'in "17 Aralık 1986, Kazakistan Olayları ve Celtoksan Şiiri” (Temiz, 1991). Yine bu olaylar hakkında çıkan kitap ise C. Kazakbalası'nın 17-18 Aralık 1986 Kazakistan Olayları (Kazakbalası 1988).

$\mathrm{Bu}$ dönemin belirtilmesi gereken son bir çalışması ise Halit Güler'in Sovyetler Birliği'nde Türkler, (Güler, 1990 ) başlıklı eseridir.

\section{Bölüm: 1991-2007}

$\mathrm{Bu}$ dönemde Türkiye'de SSCB'nin yıkılmasından itibaren Türk dünyasına yönelik araştırmalarda adeta patlama yaşanacaktır. Daha önceki bölümde bahsettiğimiz enstitü ve vakıflara ilaveten bu dönemde başta bakanlıklar olmak üzere resmi kurum ve kuruluşlar Türk dünyasına ilişkin yayın faaliyetinde öne çıkacaklardır. Ayrıca bu yıllarda Kazakistan tarihi hakkında monografiler de yayınlanmaya başlayacaktır.

SSCB'nin dağılmasından sonra, bağımsızlıklarını ilan etmiş olan Türk Cumhuriyetlerini ilk tanıyan ülke Türkiye'dir. $\mathrm{Bu}$ yeni Cumhuriyetlerle ilişkilerde önemli yeni bir kurum oluş̧urulacaktır: Dışişleri Bakanlığına bağlı olarak kurulan Türk İşbirliği ve Kalkınma Ajansı[TiKA] kısa sürede başta Kazakistan olmak üzere Türk Cumhuriyetleri ile ilgili araştırma ve yayın faaliyetlerine başlayacaktır. TíKA'nın yayına hazırladığı Kazakistan Dosyast adlı kitap (TİKA 1994) Kazakistan'1 sosyal, ekonomik, siyasi, kültürel özelliklerini tanıtmakta Kazakistan hakkında derli toplu bilgiyi vermektedir. TIKKA'nın iki önemli yayın organı olan Avrasya Bülteni ve Avrasya Etüdleri Kazakistan'ın da içinde olduğu Türk dünyasına yönelik araştırmaların çıktığı yayın organlarıdır. Avrasya Bülteni aylık dergi olup, Kazakistan başta olmak üzere Türk Cumhuriyetlerindeki gelişmeleri aktarmaktadır. Avrasya Etüdleri üç aylık dergi olup akademik niteliğe sahiptir. $\mathrm{Bu}$ dergide Kazakistan'ın güncel sorunlarına ait hem de Kazakistan'ın geçmişine ait bilimsel makaleleri görmek mümkündür.

Kültür bakanlığı ise bu dönemde Kazakistan dahil Türk Cumhuriyetlerine ilişkin yayın faaliyetlerini yoğunlaştırmış ve Türk Dünyası adıyla bir dergi de yayımlamıştır. Ahmet Bican Ercilasun'un Örneklerle Bugünkü Türk Alfabeleri (Ercilasun, 1993) adlı eserin üçüncü baskısı bu bakanlığın yayını olarak çıkmıştır. Aynı yazarın, Karşılaş̧tırmalı Türk Lehçeleri Sözlüğü (Ercilasun:1991) bakanlık yayınlarından çıkmıştır. Yine bakanlık, Büşra Ersanlı Behar'in editörlüğünü yaptığı Băgımsızlığın İlk Yılları başlıklı kitabı yayınlamıştır. (Ersanl1, 1994) Bu kitap siyaset bilimci, dış politika uzmanlarının kaleme aldığı, Kazakistan'a da ayrıntılı yer verilen bir çalışmadır. Yine aynı yazarın Türk Cumhuriyetleri Kültür Profili Araştırması bakanlıkça 1994te yayınlanmıştır. (Ersanlı, 1994) Kültür Bakanlığı'nın düzenlemiş olduğu Uluslararası Türk Dünyası Halk Edebiyatı 
Kurultayı'nın (26-28 Mayıs 2000) bildirileri bakanlıkça bastırılmıştır. (Kültür Bakanlığı: 2002) Bu kurultayda Ali Berat Alptekin, "TürkiyeAzerbaycan ve Kazakistan Aşık Şiirinde Atışma", (Alptekin: 2002) başlıklı bildirisi konumuzla ilgilidir.

Atatürk Kültür Dil Ve Tarih Yüksek Kurumu çatısı altında faaliyet gösteren Türk Tarih kurumu, Türk Dil Kurumu, Atatürk Araştırma Merkezi, Atatürk Kültür Merkezi, Kazakistan ve diğer Türk Cumhuriyetleri'nin tarihi ve kültürü hakkında telif ve çeviri kitaplar yayınlamışlardır. Türk Tarih Kurumu, Kazakistan Bilimler Akademisi Tarih ve Etnoloji Enstitüsü tarafından İngilizce olarak hazırlanan Kazakistan tarihi ile ilgili makaleler derlemesinin Türkçe çevirisini basmıştır (TTK, 2007). Kurum ayrıca arkeolojisi, sanat tarihi, folkloru hakkında Kazakçadan çeviriler yapıp yayınlamıştır. Örneğin Lezzet Tülbasiyeva'nın Kazakların Yaşam Estetiği (Tülbasiyeva, 2004); V. Şalenkenov-N.O. Aldobaer Gözenov'un Ortaçăg da Aktöbe (Şalenkeno- Gözenov 2006) gibi. Diğer yandan Hamid Ziyaev'ın Türkistan'da Rus Hakimiyetine Karşı Mücadele adlı eseri de çevrilip basılmıştır (Ziyaev, 2007). Mehmet Saray ${ }^{17}$ 'n 1993 yılında ayrı ayrı yayınladığı Kazakların tarihinin de içinde olduğu monografi dizisini, kurum toplu olarak Yeni Türk Cumhuriyetleri Tarihi başlığı altında kurum yayınlarından çıkaracaktır (Saray, 1996).

Türk Dil Kurumu, diğer Türk devlet ve topluluklarının dilleri ve kültürleri hakkında olduğu gibi Kazakça ve Kazak kültürü hakkında önemli eserleri yayınlamıştır. 6 cilt halinde Kazak Destanları Türkçe'ye kazandırılmıştır: Haz. Metin Arıkan, cilt 1, (Arıkan 2007); Haz. Metin Arıkan, cilt 2, (Arıkan: 2007); Haz. Oktay Selim Karaca, cilt 3 (Karaca: 2007); Prof. Dr. Fikret Türkmen-Yrd. Dr. Metin Arıkan (Aktaranlar), cilt 4, (Karaca: 2009); Murın Jırav Sengirbayev, (Türkmen ve Arıkan: 2007); İsmail Turan Kallimci, cilt 5, (Basım aşamasında); Seyilbek SakenovPakizat Avespayeva (haz.) (Avespayeva 2009) cilt 6. T. J. Januzagov - K. S. Esbayeva, Kazak Türklerinde Kişi Adlarl, (hzl.) Nurettin Aksu 2003, Dil Kurumu'nun önemli bir çeviri hizmeti ise, Cevat Heyet'in Türk Dilinin ve Lehçelerinin Tarihi Seyri adlı eseridir., (Heyet: 2008). Dil Kurumu'nun yürütmüş olduğu bir başka önemli proje ise, Prof. Dr. Ahmet Bican Ercilasun, Prof. Dr. Leylâ Karahan, Prof. Dr. Şükrü Haluk Akalın ile Prof. Dr. M. Fatih Kirişçioğlu'nun yürüttüğg̈ Karşılaştırmalı Türk Lehçe ve Şiveleri Sözlüğü ve Grameri Saha Araştırması başlıklı projenin ilk ürünü olan Karşılaştırmalı Türk Lehçeleri Grameri I adlı eser, 2006 yılında çıkmıştır. (Akalın: 2006)

\footnotetext{
${ }^{17}$ Mehmet Saray hakkında bkz (Bal ve Erat, 2003).
} 
Atatürk Kültür Merkezi bu dönemde içinde Kazak edebiyatı ve Kazak edebiyatçılarının da bulunduğu dört önemli eser yayınlamıştır. Bunlar, Sadık Tural'ın proje yürütücülüğünü yaptığı 9 ciltlik Türk Dünyası Edebiyatı Tarihi (Tural, 2002-2007); 8 ciltlik Türk Dünyası Edebiyatçıları Ansiklopedisi (Tural 2002-2007); 6 ciltlik Türk Dünyası Edebiyat Terimleri ve Kavramları Ansiklopedik Sözlüğü (2002-2006) ve 8 ciltlik Türk Dünyası Edebiyat Metinleri Antolojisi (2002-2007) dir. Merkez, konumuz bakımından ayrıca şu önemli eserleri de yayınlamıştır: Özkul Çobanoğlu, Türk Dünyası Ortak Atasözleri Sözlüğü (Çobanoğlu: 2004), Türk Dünyası Nevruz Şiirleri Antolojisi (AKM: 2004) ve Türk Dünyast Nevruz Ansiklopedisi (AKM: 2004). Abdimalik Nisanbayev, Kazakistan'da Dedekorkut, (Nisanbayev: 2000). Merkez, Baymirza Hayit'in makalelerini Milli Türkistan Hürriyet Davası adı altında toplamış ve yayınlamıştır. (Hayit: 2004)

Üniversitelerde bu dönemde Çağdaş Türk Lehçeleri ve Edebiyatları Bölümü arka arkaya açılmaya başlamıştır, ilk olarak A.Ü. D.T.C.F.'de 1992'de kurulmuştur. A.Ü. DTCF'de Çağdaş Türk Lehçeleri ve Edebiyatları Bölümü, gerek düzenlemiş olduğu sempozyumlar ve gerekse çıkarmakta olduğu Modern Türklük Araştırmaları Dergisi ile yoğun bir çalışma içindedir. Ankara Üniversitesi'ne bağlı Tömer, gerek dil eğitiminde Türk lehçelerine yer ayırması gerekse Türk Lehçeleri ve Edebiyatı Dergisi'ni yayınlamasıyla önemli bir hizmet sunmuştur. Ayrıca yine üniversitelerde küçük isim farkları olan ancak faaliyet alanı Kazakistan'ın içinde bulunduğu Türk dünyasına ilişkin araştırma merkezleri ve enstitüler açılmıştır: Ege Üniversitesi'nde 1992 yılında Türk Dünyası Araştırmaları Enstitüsü faaliyete geçmiş ve Türk Dünyası Incelemeleri Dergisi'ni yayınlamaya başlamıştır. Erzurum Atatürk Üniversitesi'nde, Türkiyat Araştırmaları Enstitüsü 1992'de kurulmuş, Türkiyat Araştırmaları Enstitüsü Dergisi çıkarmaya başlamıştır. Konya Selçuk Üniversitesi'nde Türkiyat Araştırmaları Enstitüsü 1991'de kurulmuş, Türkiyat Araştırmaları Dergisi adıyla bir periyodik çıkarmıştır. Hacettepe Üniversitesi, Türkiyat Araştırmaları Enstitüsü 1992'de kurulmuş, Türkiyat Araştırmaları Dergisi'ni çıkarmıştır. Gazi Üniversitesi'nde Türkiyat Araştırma ve Uygulama Merkezi 2005 yılı itibariyle faaliyete geçmiş ve Türklük Bilimi Araştırmaları Dergisi'ni çıkarmıştır. Aynı üniversitenin Fen-Edebiyat Fakültesi'nde 1992 yılında Çağdaş Türk Lehçeleri ve Edebiyatları Bölümü açılmıştır. Çukurova Üniversitesi'nde 1996 yılında Türkoloji Araştırmaları Merkezi kurulmuştur. Marmara Üniversitesi'nde ise N. Devlet (der), Milletlerarası Çağdaş Türk Alfabeleri Sempozyumu, (Devlet: 1992); M.Ü. Türkiyat Araştırmaları Enstitüsü Seminerleri 1993-1994, (MÜ: 1995); Haz. Nadir Devlet, Türk Dünyasında Nevruz (Devlet: 1999). Aynı üniversitenin Fen- Edebiyat Fakültesi 
tarafindan ise 1984 y1lında Türklük Araştırmaları Dergisi çıkarılmaya başlanmıştır. Ahmet Yesevi Üniversitesi'nin Türkiye'de çıkardığı Bilig Türk Dünyast Sosyal Bilimler Dergisi de konumuzla ilgili makaleleri içermektedir. Üniversite ayrıca Asyavrupa adlı Türk dünyasını ilgilendiren bir başka dergiyi de çıkarmaya başlamıştır.

Geçen dönemde bahsedilen Türk Kültürünü Araştırma Enstitüsü, Türk Dünyası Araştırmaları Vakfı bu dönemde de faaliyetlerini kazak tarihi ve kültürünü de içerecek şekilde dergi ve kitaplarıyla sürdürmüşlerdir. Örneğin Türk Kültürünü Araştırma Enstitüsü 1976'da basmış olduğu Türk Dünyası El Kitabı'nın genişletilmiş yeni bir baskısını yapmıştır. (TKAE: 1992)

Hasan Celal Güzel'in öncülüğünde Yeni Türkiye Yayınları editörlüğünü Hasan Celal Güzel, Kemal Çiçek, Salim Koca'nın yaptığı geniş bir akademik kadro ile 21 ciltlik Türkler Ansiklopedisi'ni yayınlamıştır (Güzel, Çiçek ve Koca: 2002). Ansiklopedinin 18. ve 19. ciltleri Türk devlet ve topluluklarına ayrılmıştır.18. ciltte Kazak tarihinin değişik dönemleri ile ilgili makaleler vardır. Örneğin Gülnar Kandirboi'nin "Alaş" Svetlana Kovalskaya'nın "Kazakistan'da Cedidcilik" gibi. Cilt 19'da ise Kazakistan ülke olarak tarih, ekonomi, sosyal durum itibariyle ayrıntılı olarak incelenmiştir (cilt 19 s. 317-447). İkinci önemli çalışma ise, editörlügünü Hasan Celal Güzel ve Ali Birinci'nin yaptığ 10 ciltlik Genel Türk Tarihi de (Güzel ve Birinci: 2002) önemli bir başka ansiklopedik çalışmadır. 10. ciltte Manas Kazıbaev ve Salter Mazıdov Kazakistanla ilgili kısımları yazmışlardır. Aynı şekilde Yeni Türkiye yayın grubunun çıkarmış olduğu Yeni Türkiye Dergisi'nin 43, 44, 45 ve 46. sayıları Türkoloji ve Türk Tarihi Araştırmaları'nın özel sayıları olarak çıkmıştır. Yine aynı derginin 15 ve 16. sayıları Türk dünyası özel sayıları olarak çıkmıştır.

$\mathrm{Bu}$ dönemde makaleleriyle ve kitaplarıyla Kazak tarihi ve kültürünü araştıran, Türk okuyucusuna Kazak tarihi ve kültürünü tanıtan yazarlardan da bahsetmek yararlı olacaktır. İstanbul Üniversitesi Edebiyat Fakültesi Tarih Bölümü öğretim üyelerinden Mehmet Saray 1970'lerden itibaren ilgilendiği, eserler verdiği eski SSCB içindeki Türk devlet ve topluluklarına ilişkin yayın faaliyetini bu dönemde sürdürmüştür. Mehmet Saray 1993 yılında Kazak Türkleri adlı monografisini yayınlar. (Saray: 1993) M. Saray'ın Kazakistan'ın bölüm olrak işlendiği Yeni Türk Cumhuriyetleri Tarihi kitabı ise Türk Tarih Kurumunca 1996'da yayınlanır. (Saray: 1996) 2004 yılında ise TİKA M. Saray'ın Kazakların Uyanışı- Kazakistan Tarihini yayınlar. Bu çalışma bir Türk bilim adamının telif olarak en kapsamlı kazak tarihi denemesidir. (Saray: 2004) 
Ankara Üniversitesi Dil ve Tarih-Coğrafya Fakültesi Tarih Bölümü öğretim üyelerinden Saadettin Gömeç Türk Cumhuriyetleri ve Toplulukları Tarihi başlıklı eserinde (Gömeç:2003), II. Bölüm olarak Kazakistan'1 işlemiştir.

Kazakistan ve diğer Türk Cumhuriyetlerinin bağımsızlıklarının 10. yılındaki durumları hakkında vurgulanması gereken önemli bir çalışmadır. Emine Gürsoy Naskali-Erdal Şahin'in yayına hazırladığı Bağımsızlıklarının 10. yılında Türk Cumhuriyetleri, Kazakistan'a ayrılan bölümü ile önemli bir çalışmadır (Naskali ve Şahin: 2002).

Ayşe Yücel Çetin'in Hacettepe Üniversitesi'nde Kazak halk edebiyatı hakkında yapmış olduğu ve Kazakistan Sahası Halk Hikâyeciliği Geleneği, adı ile basılan doktora çalışması da (Çetin: 2003) bu dönemin dikkate değer önemli monografi çalışmalarındandır.

Karadeniz Teknik Üniversitesi öğretim üyelerinden Alaeddin Yalçınkaya, Almatı'dan Akmola'ya Kazakistan'ın Başkenti isimli eseri (Yalçınkaya: 1997) Rus egemenliğinin başlangıcından 1996ya kadar bir Kazak tarihi denemesidir.

Kazakistan'la ilgili olarak şu monografileri de belirtmemiz gerekiyor. Kayyum Kesici, Dün, Bugün ve Hedefteki Kazakistan, (Kesici: 2003); Abdülvahap Kara, Kazakistan'in Yeniden Doğuşu 1986, Aralık Olayları (Kara: 2007); Mustafa Kalkan, Kirgızlar ve Kazaklar (Kalkan: 2006 ); Mehmet Ziya Binler, Türk Dünyast Aile ve Akrabalık Terimleri Sözlüğ̈̈ (Binler: 2007); Feyzullah Budak, Kazakistan, Dünü-Bugünü-Yarını (Budak: 1999). Kemal Karpat'ın Türkiye ve Orta Asya (Karpat: 2003), isimli çalışması yazarın makalelerinin bir derlemesidir.

$\mathrm{Bu}$ dönemde Türk Kültürünü Araştırma Enstitüsü ile Türk Dünyası Araştırmaları Vakfı'nın yanı sıra yeni vakıflar ve araştırma merkezleri de kurulup Türk Dünyası ile ilgili yayın faaliyetine girişmişlerdir. Dönemin önemli bir kurumu olarak Avrasya Bir Vakfi 1993 yılında kurulup, ardından bu vakfa bağlı olarak Avrasya Stratejik Araştırmaları Merkezi (ASAM) faaliyete geçmiştir. ASAM, 2000 yılında Stratejik Analiz dergisini çıkarmaya başlar. Bu dergide Kazakistan'la ilgili yazılar da vardır. ASAMın bir diğer önemli yayın organı Avrasya Dosyası adlı dergisidir. Bu derginin özel dosyaları dünya politikasında ve Türk dış politikasında önemli yeri olan ülke incelemelerine ayrılmıştır. Avrasya Dosyası'ın cilt:7 sayı:4 (2001)ü Kazakistan-Kırgızistan doyası olarak çıkmıştır. ASAMın kitaplarından Anar Somuncuoğlu'nun Kazakistan ve Özbekistan Ekonomileri Geçiş ve Büyüme Stratejileri (Ankara, 2001) başlıklı eseri Kazakistan'ın ekonomik gelişmesini Türk okuyucusuna tanıtan önemli bir monografidir. Dönemin unutulmaması 
gereken bir özel kurum faaliyeti de Türk Kültürüne Hizmet Vakfı'nın çok ayrıntılı Türk Dünyası Kültür Atlası'dır (Naskali 2003). Emine Gürsoy Naskali-Ahmet Taşağıl'ın editörlüğünü yaptığı bu eserin bir bölümü Kazakistan'a ayrılmıştır. Ayrıca Kök Sosyal ve Stratejik Araştırmalar Vakfi 1991 yılında kurulup yayın ve araştırma faaliyetine başlamıştır. Vakıf, Kök Araştırmaları adında bir dergi ile Tengrim Türklük Bilgisi serisi adı altında Türklük araştırmalarına ilişkin kitaplar yayınlamıştır.

$\mathrm{Bu}$ dönemin Kazak tarihi ve kültürüyle ilgili önemli bir yayın grubu da çeviri yolu ile Türkçe'ye aktarılan eserlerdir. Türk Tarih Kurumunun Kazakistan tarihi çevirisinden yukarıda bahsetmiştik. Selenge Yayınevi, iki önemli eseri çevirmiştir. Birincisi, S:G. Klyashtorny-T.İ. Sultanov’un Ahsen Batur tarafından çevrilen Kazakistan Türk'ün Ü̧̧ Bin Yllı (Klyashtorny ve Sultanov: 2003). İkincisi, Kazakistan Bilimler Akademisi tarafindan hazırlanan Kazakistan ve Kazaklar, adıyla Abdülvahap Kara tarafından çevrilen eserdir. (KBA: 2007). Pakistanlı yazar Ahmet Raşit'in Orta Asya'nın Dirilişi-İslam mi, Milliyetçilik mi? Çeviren Osman Deniztekin, başlıklı eseri Cep yayınevi tarafından yayınlanmıştır (Raşit: 1996). Kitabın bir bölümü Kazakistan'a ayrılmıştır. Kazakistan cumhurbaşkanı Nursultan Nazarbayev'in Kazakistanın dış politikasında Avrasya perspektifi hakkında bir incelemesi olan Rus yazar Aleksandr Dugin'in kitabı Türkçeye Nursultan Nazarbayev'in Avrasya Misyonu adıyla Lazzat Urakova ve Nehriban Gençkal tarafından çevrilmiş ve yeni Avrasya Yayınevi tarafından basılmıştır (Dugin: 2006). Semih Vaner'in Fransızca'dan Türkçe'ye Unutkan Tarih Sovyet Sonrası Türk Dilli Alan adıyla çevrilen derlemesi önemli bir kaynaktır. Ercan Eyüboğlu tarafından çevrilip metis yayınlarının 1997de bastığı bu çalışmanın bir bölümü Fransız yazar Alain Giroux’un "Kazakistan: Asya Devinin Potansiyeli ve Ekonomik Modeli" makalesi oluşturmaktadır. (Vaner: 1997) Bir başka önemli çeviri, yine Metis yayınlarından çıkan, Fransız araştırmacı yazar Olivier Roy'un Yeni Orta Asya ya da Ulusların Imal Edilişi başlıklı eseridir. 2000 yılında Mehmet Moralı tarafından çevrilen kitap genel nitelikte olup Rusya'nın bölgeyi ele geçirmesinden SSCB'nin dağılması sonrası bölgenin sorunlarına ilişkin konuları bu arada Kazakistan ve diğer Türk Cumhuriyetleri bağlamında incelemektedir.(Roy: 2000). İletişim Yayınları ise, Joma Nazpary'nin Selda Somuncuoğlu tarafindan Türkçe'ye Sovyet Sonrası Karmaşa Kazakistan'da Şiddet ve Mülksüzleşme adıyla çevrilen eserini yayınlamıştır. (Nazpary: 2003)

$\mathrm{Bu}$ dönemde Türk üniversitelerinde kazak öğrenciler tarafindan sosyal bilimler alanında lisansüstü tezler yapılmıştır. Özellikle A.Ü. Sosyal Bilimler Enstitüsü'nde iktisat, işletme ve uluslar arası ilişkiler anabilim dallarında 
yüksek lisans ve doktora programlarında Kazak öğrenciler Kazakistan'ın ekonomisi ve dış politikasına ilişkin konular seçerek tezlerini yazmışlardır. Örneğin Aigül Davlyatchina, uluslar arası ilişkiler bölümünde yüksek lisans tez konusu olarak NATO ve Kazakistan'1 seçmiş ve hazırlamıştır. (Davlyatchina, 2007) Smaiyl Karlygash ise işletme bölümünde Kazakistan Bankacılık Sektörünün Durumu ve İktisadi Kalkınmadaki Rolü'nü yüksek lisans tez konusu olarak seçmiş ve hazırlamıştır (Karlygash, 2001).

\section{Sonuç}

Türkiye'de Kazakistan tarihi ve kültürüne ait araştırmaların 1923-2009 yılları arasındaki 83 yıllık serüvenine baktığımızda şu sonuçları çıkarmamız mümkün:

Daha 1924 yılında Türkiyat Enstitüsü'nün kurulması, Türkiye dışındaki Kazaklar dahil Türk kökenli halkların tarih ve kültürü ile bilimsel olarak ilgilenecek, üniversite bünyesinde bir kuruma işaret eder. Bu daha sonraki y1llarda benzer nitelikli girişimleri başlatan kişilerin akademik kariyerden gelmeleri geleneğinin başlangıcı olacaktır. 1961de kurulan Türk Kültürünü Araştırma Enstitüsü, 1980 'de kurulan Türk Dünyası Araştırmaları Vakfı ve 1990lardaki Avrasya Stratejik Araştırmaları Merkezi[ASAM] gibi kuruluşların kurucuları da akademik kariyerden gelen insanlar olacaklardır.

Devletin dışındaki, örneğin Türk Ocakları, 1950lerde Türk Milliyetçilik Derneği gibi kuruluşlar yayınları, konferansları ile Kazaklar dahil Türkiye dışındaki Türk halklarının tarih ve kültürüne Türk kamuoyunun dikkatini çekmeğe çalışmışlardır.

1931 yılında Nihal Atsı'ın Atsız Mecmuası ile başlayıp günümüze kadar devam eden popüler nitelikteki Türkçü dergilerin Türk kamuoyunun dikkatini Türkiye dışındaki Kazaklar dahil Türk halklarının varlığına çekmekte başarılı olmuşlarıdır.

Kazakça, akademik olarak diğer Türk lehçeleri ile birlikte 1936'dan itibaren A.Ü. D.T.C.F.nde öğretilmeye başlamıştır. Konuyla ilgili olarak Saadet Çağatay 1961'de Kazakça Metinler adıyla kitap çıkarmıştır.

1950li yılların iki önemli yayın faaliyeti Kazak aydını Mustafa Çokay'ın hayatını ve faaliyetlerini Türk kamuoyuna tanıtan bir kitabın çıkması ile İslam Ansiklopedisi'nde Kazakistan'la ilgili derli toplu bilginin Reşit Rahmeti Arat tarafından yazılmasıdır.

Kazaklar dahil Türkiye dışında Türk kökenli halkların tarih ve kültürüyle ilgili genel nitelikli çalışmaları 1928de Yusuf Akçura'nın Türk Yılı başlıklı hacimli derlemesiyle başlatmak mümkün. Bu genel nitelikli eser Türkiye'de bir öncü eser olmuş 1928'den sonra da bir geleneği başlatmış, 
1940'l1 yıllarda Abdullah Recep Baysun ile Lajos Rasonyi'nin, Hüseyin Namık Orkun'un, Zeki Velidi Togan'ın 1970li y1llarda Türk Kültürünü Araştırma Enstitüsü'nün Türk Dünyası El Kitabı, 1980lerde Nadir Devlet'in Çağdaş Türk Dünyası, 1990larda Mehmet Saray, Yeni Türk Cumhuriyetleri Tarihi, Saadettin Gömeç, Türk Cumhuriyetleri ve Topluluklart Tarihi adlı eserleri ile bu geleneği devam ettirmişlerdir.

1970 başlarından itibaren akademik dünya dışından, özellikle Hasan Oraltay Kazak tarihi, kültürü konusunda yayınları başlatmış böylece Kazak tarihi ve kültürü hakkında Türk kamuoyu ayrıntılı monografilere kavuşmuştur. Yine aynı yıllarda kolektif bir çalışma olan Kazaklar Tatarlarda konumuzla ilgili monografik çığırın devamı olmuştur.

SSCB'nin dağılmasından kısa bir süre önce 1986 Aralık ayında Kazakistan'da çıkan olaylar kitap ve makalelerle Türk kamuoyuna aktarılmış, Kazakistan Türk kamuoyunun gündemine girmiştir.

SSCB'nin dağılması ve Kazakistan'ın bağımsızlığını ilan etmesiyle birlikte 19901 yıllar konumuzla ilgili bir yayın patlamasına tanık olmuştur. Artık, Türkiye Cumhuriyeti'nin resmi organ ve kuruluşları, bakanlıkları, Dışişleri Bakanlığı-buna bağlı Türk İşbirliği ve Kalkınma Ajansı TİKA, Kültür Bakanlığı, Milli Eğitim Bakanlığı Kazakistan dahil Türkiye dışındaki Türk Cumhuriyetleriyle ilgili araştırma-yayın faaliyetlerine girişmişlerdir. Buna Türk Tarih Kurumu, Dil Kurumu, Atatürk Kültür Merkezi gibi kurumları da eklemek gerekiyor.

Doğrudan Kazakistan tarihi ve kültürüyle ilgili telif veya çeviri yayınlarda bir artış gözlenmiştir bu dönemde.

Üniversiteler 199011 y1llarda da konumuzla ilgili olarak hem kurumlar yani bünyelerindeki Türkoloji araştırmalarıyla ilgili merkezler, enstitüler ve bu enstitülerde yayın ve sempozyum faaliyetleri ile Kazakistan dahil Türkiye dışındaki Türk devlet ve toplulukların tarih ve kültürlerine yönelik önemli araştırmalarda bulunmuşlardır.

1923 ten 2009'a uzanan 86 y1lda Türkiye'de Kazakistan tarihi ve kültürü hakkında çıkan yayınlarla ilgili bu genel nitelikli envanter çalışması, bize konuyla ilgili önemli bir bilgi birikiminin sağlanmış olduğunu göstermiştir. Böylelikle Kazakistan tarihi ve kültürü hakkında, özellikle Türk bilim adamları tarafından Türk - Kazak hükümetleri ve üniversitelerinin işbirliği ile daha ayrıntılı, derinlikli çalışmaların, monografilerin yapılacağı ileri bir aşamaya geçişin koşulları tamamlanmıştır. 


\section{Kaynakça}

AKALIN, Şükrü Haluk-ERCILSUN, Ahmet Bican, KARAHAN, Leyla, KİRİ̧̧̧̧iOĞLU, Fatih, (2006), Karşılaştırmalı Türk Lehçeleri Grameri, I, TDK, Ankara.

AKÇURA, Yusuf, (1928), Türk Yıll, İstanbul

60. Doğum yılı Münasabetiyle Zeki Velidi Togan'a Armağan, (1950), İstanbul.

ALANBEK, M, (1987), Kazakistan'da İsyan, Türk Yurdu, 8-8

ALAŞ, (1973), Türkistan Türklerinin Milli İstiklal Parolası, Büyük Türkeli Yay., İstanbul

ARAT, R. Rahmeti, (1955), Kazakistan, MEB, $\dot{I} A, 6,494-505$.

ARIKAN, Metin, (2007), Kazak Destanlarl, I, TDK. Yayını, Ankara

ARIKAN, Metin, (2007), Kazak destanları, II. TDK, Ankara

ARIKAN, Metin, TÜRKMEN, Fikret, (2007), Kazak destanlarl, IV, TDK, Ankara

ASAM, (2001), Avrasya Dosyası, 7-4.

AKM, (2004), Türk Dünyası Nevruz Şiirleri Antolojisi, Atatürk Kültür Merkezi yayını, Ankara.

AKM, (2004), Türk Dünyası Nevruz Ansiklopedisi, Atatürk Kültür Merkezi yayını, Ankara.

Atsız Armă̆anı, (1976) Ötüken Yayınevi, İstanbul,

AVESPAYEVA, Pakizat-SEYİLBEĞ, Sakenov, (2009), Kazak Destanları, VI, Haz. Oktay Selim Karaca TDK, Ankara

BAL, H.; ERAT, M., (2003), Mehmet Saray'a Armağan-Türk Dünyasına Bakışlar, Da yayıncılık, İstanbul.

BARTHOLD, V.V., (1928), Orta-Asya Türk Tarihi Hakkında Dersler, Türkiyat Enstitüsü Yayın1, İstanbul

BAYKARA, T., (1986), Zeki Velidi Togan, Kültür bakanlığg Yay., Ankara.

BAYSUN, Abdullah Recep, (1943), Türkistan Milli Hareketleri, İstanbul

BİLGİÇ, E., EREN, H., TURAN, O., (1953), 60. Doğum Yılı Münasebetiyle Fuat Köprülü Armağanı, İstanbul.

BİNLER, Mehmet Ziya, (2007), Türk Dünyası Aile ve Akrabalık Terimleri Sözlüğü, Selenge yayınları, İstanbul

BİRINCİ, Ali, GÜZEL, Hasan Celal, (2002) Genel Türk Tarihi, Yeni Türkiye Yayınları

BUDAK, F. (1999), Kazakistan, Dünü-Bugünü-Yarını, Ocak Yayınları, Ankara.

CAFEROĞLU, A., (1965), Kazak Türkleri, Türk Kültürü, 3- 29

ÇAĞATAY, Sadet, (1950), Türk Lehçeleri Örnekleri VIII-XVIII Yüzyıla Kadar Yazı Dili, A.Ü. DTCF Yayını, Ankara

ÇAĞATAY, Sadet, (1961), Kazakça Metinler, A.Ü. DTCF Yayını, Ankara

ÇAĞATAY, Sadet, (1972), Türk Lehçeleri Örnekleri, A.Ü. DTCF Yayını, Ankara

ÇAĞATAY, Sadet, (1978), Türk Lehçeleri Üzerine Denemeler, A.Ü. DTCF yayını, Ankara

ÇETiN, A. Y. (2003), Kazakistan Sahası Halk Hikâyeciliği Geleneği, Ankara. 
ÇİÇEK, Kemal, GÜZEL, Hasan Celal ve KOCA Salim, (2002), Türkler Ansiklopedisi, Yeni Türkiye Yayınları, Ankara

ÇOBANOĞLU, Özkul, (2004), Türk Dünyası Ortak Atasözleri Sözlü̆̆̈̈, Atatürk Kültür Merkezi Yayını Ankara.

ÇOKER, F., (1983), Türk Tarih Kurumu-Kuruluş Amacı ve Çalışmaları, TTK Yayını, Ankara.

DARENDELİOĞLU, İ., (1968), Türkiye'de Milliyetçilik Hareketleri, İstanbul.

DAVLYATCHİNA, A. (2007), NATO ve Kazakistan A.Ü. SBF Sosyal Bilimler Enstitüsü Yüksek Lisans Tezi.

DEVLET, N., (1985), Rusya Türklerinin Milli Mücadele Tarihi 1905-1917, Türk Kültürünü Araştırma Enstitüsü Yayını, Ankara

DEVLET, N., (1989), Çağdaş Türk Dünyası, M.Ü. Fen-Ed. Fak. Yayınları, İstanbul

DEVLET, N. (der), (1992), Milletlerarası Çağdaş Türk Alfabeleri Sempozyumu, İstanbul.

DEVLET, N. (haz.) (1999), Türk Dünyasında Nevruz, Marmara Üniversitesi Yayınları, İstanbul.

DÖNMEZ, Y., (1987), Türk Dünyasının Beşeri ve İktisadi Coğrafyası, İstanbul Üniversitesi Edebiyat Fakültesi Yayını.

DUGíN, A. (2006), Nazarbayev'in Avrasya Misyonu, Çev., Lazzat Urakova, Nehriban Gençkal, Yeni Avrasya Yayınevi, Ankara.

ENGIN, M. (1976), Kazak ve Tatar Türkleri, Boğaziçi Yay., İstanbul.

ERCİLASUN, (1993), A. B. Örneklerle Bugünkü Türk Alfabeleri, Ankara.

ERSANLI, B. (1994), Türk Cumhuriyetleri Kültür Profili Araştırması. Kültür Bakanlığı Yay., Ankara.

ERSANLI, B. (1994), Bağımsızlı̆̆ın İlk Yılları, Kültür Bakanlığı Yay., Ankara.

ESBAYEVA, K.S., (2003), Kazak Türklerinde Kişi Adları, Haz. Nurettin Aksu, TDK, Ankara

GEORGEON, F., (1986), Türk Milliyetçiliğinin Kökenleri-Yusuf Akçura (1876-1935), Yurt Yay., Ankara.

GÖMEÇ, S., (1999),Türk Cumhuriyetleri ve Toplulukları Tarihi, Akçağ Yayınları Ankara,.

GÜLER, H. (1990), Sovyetler birliğinde Türkler, Diyanet Vakfi Yayını, Ankara.

http://www.turan.org.tr

http://www.alibeghakim.com

HAYİT, Baymirza, (1971), Türkistan'da Öldürülen Türk Şairleri, Ankara

HAYİT, Baymirza, (1975), Türkistan, Rusya ile Çin Arasında, Çev., Abdülkadir Sadak, Otağ Yayınları, İstanbul

HAYİT, Baymirza, (2004), Milli Türkistan Hürriyet Davası, Atatürk Kültür Merkezi Yayını, Ankara

HAYMANA, Münir, YAYLAGİL, A., (1937), Hali Hazırın Türk Topluluklart ve PanTürklüğe Dair, İstanbul 
HEYET, Cevat, (2008), Türk Dilinin ve Lehçelerinin Tarihi Seyri, Çev. Mürsel Öztürk, TDK, Ankara

İLGÜREL, S. (1975), Türkiyat Enstisüsü, Türk Kültürü, 14-158.

İNAN, A. (1998) Makaleler, Incelemeler, 2 Cilt, Türk Tarih Kurumu Yayını.

İstanbul Darülfünunu Türkiyat Enstitüsü, (1931), Evkaf Matbaası, İstanbul.

KALKAN, Mustafa, (2006), Kırgızlar ve Kazaklar, Selenge Yayınları, İstanbul

KANDİRBOİ, G. (2002), Alaş Türkler Ansiklopedisi, 18, Ankara.

KARA, A. (2007), Kazakistan’ın Yeniden Doğuşu 1986 Aralık Olayları, Ufuk Ötesi Yayınları, İstanbul.

KARACA, Oktay Selim, (2007), Kazak Destanlarl, III, TDK, Ankara

KARLYGASH, S. (2001), Kazakistan Bankacılık Sektörünün Durumu ve İktisadi Kalkınmadaki Rolü A.Ü. SBF Sosyal Bilimler Enstitüsü Yüksek Lisans Tezi,.

KARPAT, K. (2003), Türkiye ve Orta Asya, İmge Yay., Ankara.

KAZAKBALASI, C., (1988)17-18 Aralık 1986 Kazakistan Olaylarl, Büyük Türkeli Yayınları, İstanbul.

Kazakistan Bilimler Akademisi (2007), Kazakistan ve Kazaklar, Çev. Abdulvahap Kara, (İstanbul).

KESİCI, K. (2003), Dün, Bugün ve Hedefteki Kazakistan, IQ Yayınları, İstanbul.

KLYASHTORNY S.G. - SULTANOV T.İ. (2003), Türk'ün Üç Bin Yıll, Çev. Ahsen Batur, Selenge Yayınevi, İstanbul,

KOVALSKAYA, S. (2002), Kazakistan'da Cedidcilik, Türkler Ansiklopedisi, 18, Ankara.

KÖPRÜLÜ, F, (1953), 60. Doğum Yılı Münasebetiyle Fuat Köprülü Armağanı, İstanbul.

LANDAU, J. (1999), Pantürkizm, Çev. Mesut Akın, Sarmal Yayınları, İstanbul.

Marmara Üniversitesi (1995) Türkiyat Araştırmaları Enstitüsü Seminerleri 1993-1994, İstanbul.

LİGETİ, L.(1946), Bilinmeyen İç Asya, Ankara.

NASKALİ, Emine Gürsoy, ŞAHİN, Erdal, (2002), Bağımsızlıklarının 10. Yılında Türk Cumhuriyetleri, Hollanda

NASKALİ, Emine Gürsoy, TAŞAĞIL, Ahmet, ( 2003), Türk Dünyası Kültür Atlası, Türk Kültürüne Hizmet Vakfi, İstanbul

NISANBAYEV, Abdülmalik, (2000), Kazakistan'da Dede Korkut, Atatürk Kültür merkezi, Ankara.

ORALTAY, H., (1961), Kazak Türkleri Hürriyet Ŭgrunda Doğu Türkistan, İstanbul.

ORALTAY, H., (1978), Kazak Türklerinin Çadırları, Türk Kültürü 16-192

ORALTAY, H., (1984), Kazak Türkçesi Sözlügü, Türk Dünyası Araştırmaları Vakfı Yayını

ORKUN, Hüseyin Namı, (1932), Türk Dünyası, İstanbul

ORKUN, Hüseyin Namık, (1944), Yeryüzünde Türkler, İstanbul 
OKTAY, A., (1950), Türkistan Milli Hareketi ve Mustafa Çokay, İstanbul

OKTAY, A. (1952), Türkistan'a Dair Bazı Cereyanlar Hakkında Görüşlerimiz, İstanbul ÖZDEMIR, H; ŞENOL, H., (2006), DTCF'de Türkoloji'nin Öyküsü, Ankara.

RASONYİ, L.(1942), Dünya Tarihinde Türklük, Ankara.

RAŞíT, A., (1996), Orta Asya'nın Dirilişi-İslam mı, Milliyetçilik mi? Çev. Osman Deniztekin, Cep yayınevi, İstanbul.

ROY, O. (2000)Yeni Orta Asya'da Ulusların Imal Edilişi, Çev. Mehmet Moral, Metis yayınlar1.

SARAY, M. (1975), Rusya'nın Türk İllerinden Yayılması, İstanbul.

SARAY, M. (1984), Rus işgali devrinde Osmanlı Devleti ile Türkistan Hanlıkları Arasındaki Siyasi Münasebetler (1775-1875), İstanbul Matbaas1.

SARAY, M. (1996), Türk Cumhuriyetleri Tarihi, Türk Tarih Kurumu Yayını, Ankara.

SARAY, M. (1988), Dış Türkler, MEB, İA, 12/2, 409-445

SARAY, M., (2004), Kazakların Uyanışı-Kazakistan Tarihi, TİKA, Ankara

SARINAY, Y., (2004), Türk Milliyetçiliğinin Tarihi Gelișimi ve Türk Ocakları, 2. bask1, Ötüken yayınları, İstanbul.

ŞALENKENOV, V. - GÖZENOV N.O.A. (2006) Ortaçağda Aktöbe, Türk Tarih Kurumu Yayını, Ankara.

SOMUNCUOĞLU, A. (2001) Kazakistan ve Özbekistan Ekonomileri Geçiş ve Büyüme Stratejileri, Ankara.

TEMIZ, S. (1991), 17 Aralık 1986 Kazakistan Olayları ve Celtoksan Şiiri, Türk Yurdu, 11.

TOGAN, Z. V., (1940), 1929-1940 Seneleri Arasında Türkistan Vaziyeti, İstanbul.

TOGAN, Z. V., (1942), Bugünkü Türkili -Türkistan-ve Yakın Tarihi, İstanbul.

TOGAN, Z. V., (1946), Umumi Türk Tarihine Giriş, İstanbul.

TOGAN, Z. V., (1969), Hatıralar, İstanbul.

TOGAN, Z. V., (1970), Türklügün Mukadderatı Üzerine, İstanbul.

TTK (2007), Kazakistan Tarihi Makaleler, Ankara.

TURAL, S., (2002-2007)Türk Dünyası Edebiyatı Tarihi, Atatürk Kültür Merkezi Yayını, Ankara.

TURAL, S., (2002-2007) Türk Dünyası Edebiyatçıları Ansiklopedisi, Atatürk Kültür Merkezi Yayın1, Ankara.

TURAL, S., (2002-2006) Türk Dünyası Edebiyat Terimleri ve Kavramları Ansiklopedik Sözlüğü, Atatürk Kültür Merkezi Yayını, Ankara.

TURAL, S., (2002-2006), Türk Dünyası Edebiyat Metinleri Antolojisi, Atatürk Kültür Merkezi Yayını, Ankara.

TÜLBASIYYVA, L., (2004) Kazakların Yaşam Estetiği, Türk Tarih Kurumu Yayını, Ankara.

TKAE, (1976) Türk Dünyası El Kitabı, Türk Kültürünü Araştırma Enstitüsü, Ankara. 
VANER, S. (1997)Unutkan Tarih Sovyet Sonrası Türk Dilli Alan Çev. Ercan Eyüboğlu, Metis yayınları

Y.T., (1951-1954), Türkistan'da Türkçülük ve Halkçılık, İstanbul

YALÇINKAYA, A. (1997) Almatı'dan Akmola'ya Kazakistan'ın Başkenti, Sakarya.

ZIYAEV, H. (2007) Türkistan'da Rus Hakimiyetine Karşı Mücadele, Türk Tarih Kurumu Yayını, Ankara. 